\title{
ERRATUM
}

\section{Erratum to: Di-peptidyl peptidase-4 inhibitor sitagliptin protects vascular function in metabolic syndrome: possible role of epigenetic regulation}

\author{
Cicek Figen Amber • Tokcaer-Keskin Zeynep • \\ Ozcinar Evren · Bozkus Yusuf • Akcali Kamil Can • \\ Belma Turan
}

Published online: 12 June 2014

(C) Springer Science+Business Media Dordrecht 2014

\section{Erratum to: Mol Biol Rep}

DOI 10.1007/s11033-014-3392-2

Co-author first name and surname were interchanged in the original publication and should be correctly read as Belma Turan.

The online version of the original article can be found under doi:10.1007/s11033-014-3392-2.

C. F. Amber · T.-K. Zeynep · A. K. Can · B. Turan ( $₫)$

Department of Biophysics, Faculty of Medicine,

Ankara University, Ankara, Turkey

e-mail: belma.turan@medicine.ankara.edu.tr

\section{O. Evren}

Department of Cardiovascular Surgery, Faculty of Medicine, Ankara University, Ankara, Turkey

B. Yusuf

Department of Endocrinology and Metabolism, Faculty of

Medicine, Baskent University, Ankara, Turkey 